\title{
Educational results from blended learning: Using an educational platform in teaching Economics
}

\author{
Vasiliki Brinia \\ Athens University of Economics and Business \\ Email: vbrinia@aueb.gr \\ Panagiotis Kavaliarakis \\ Hellenic Open University
}

Received: February 18, 2015 Accepted: February 23, 2016 Published: April 26, 2016

Doi:10.5296/ ijld.v6i1.9282 URL: http://dx.doi.org/10.5296/ ijld.v6i1.9282

\begin{abstract}
This research investigates the learning result of applying blended learning with the combined use of open educational platform and traditional teaching. This educational intervention took place during the course Principles of Economic Theory in the 3rd grade of High School. We measured the differences in student performance in an assessment test before and after the educational intervention, but also the changes in their attitude as to the course of the economy, itself. Moreover, we evaluated the students' satisfaction from using the open educational platform, but also the social presence which was created. The results led to the conclusion that hybrid teaching methods, can be used in the teaching of Economics and is considered as important as traditional ones.
\end{abstract}

Keywords: Blended learning, attitudes towards the economy, social presence, learning result, students' satisfaction.

\section{Introduction}

A key element of the new learning environment is distance learning which provides important flexibilities to the students. According to Holmberg (1983), distance learning includes the various forms of education at all levels, which have no direct and continuous presence of educators in classrooms, but benefit from the organization, guidance and teaching of an educational organization.

The combination of traditional forms of teaching with multiple educational and technological methods is a fast growing approach called blended learning. In blended learning, educators use different types of teaching, such as a web-based teaching and a face to face teaching method. Furthermore, they use the Internet to enhance conventional teaching and they combine parts of training that does not require special guidance, with those in which the presence and guidance of the teacher are necessary. Such mixed approaches affect social identity and social relations of learners, the operation of the working groups and 
the decision-making process, such as advisory, facilitation and the overall role of the instructor (Bonk, Olson, Wisher \& Orvis, 2002).

This specific educational approach of blended learning could be very useful in the teaching of economics. The economics courses in High school, although they do not present particular difficulties in terms of understanding, they have the special feature of combining knowledge of different disciplines such as mathematics, sociology, history and political studies (Nelson, 1977). This interdisciplinary dimension of economics demands autonomy in learning that includes critical thinking, impartiality, independence, taking timely decisions but also easy access to the world of ideas (Lim, 2003).

The purpose of this research is to investigate the educational teaching of blended learning, using an open educational platform, in addition to conducting the course with the traditional teaching methods.

Other objectives of the research were to investigate whether:

1. Teaching a learning object with the additional use of an educational platform produces better learning outcomes than traditional face to face teaching.

2. Teaching a learning object with additional use of an educational platform contributes to shaping positive attitudes towards the learning object, in comparison to the traditional face to face teaching.

3. The students who were taught by using a complementary training platform were satisfied by the learning process.

4. The students who are taught by this educational platform developed the sense of social presence because of its use.

For this purpose we used the educational platform «Khan Academy» which is freely accessible online in https://www.khanacademy.org. We used it to implement blended learning in teaching the course "Principles of Economic Theory" in the $3^{\text {rd }}$ grade of High School.

\section{Theoretical Background}

The literature review revealed that the efforts of implementing blended learning in teaching economics have conflicting conclusions. There were positive results in studies such as Agarwal and Day (1998) who carried out a survey in control groups and experimental groups during the course «Principles of Macroeconomics". Their research showed that the Internet has a positive effect on learning of economics, on the attitude towards the economics courses and on the students' perceptions regarding the effectiveness of the teacher. Their research tools were the measurement of student performance before and after teaching by using internet, final grades and the standardized assessment test "Test of Understanding in College Economics" (TUCE).

The survey of Sosin et al. (2004) showed that the use of Information and Communications Technology (ICT) in teaching economics as a whole has a small but positive effect on students' achievement. The survey was conducted in 2002, in teachers and students of fifteen (15) universities. The research was conducted during the course of "Applied economics" using the presentation through Power Point, the electronic mail (e-mail), online courses (WebCT) and the Test of Understanding in College Economics (TUCE) to evaluate the performance.

Talley (2000) studied four (4) macroeconomics classes; one in which face to face learning was used and three online classes. The research was conducted in the Dacota State University. In one of the online classes, students could watch a videotaped session of the lesson. The research showed that only this particular class showed higher scores on final exams, compared to the other classes. 
Navarro (2000) investigated the effect of blended learning in economics, through the views of the educators who were trained in a new educational program. For the majority of trainees who were given digital material notes and passages of the textbook, the satisfaction and attitude towards the course were the same or even better, than those who followed the traditional way of teaching.

However, there were negative results with respect to the implementation of blended learning in the research of Brown and Liedholm (2002), who studied three classes of students of the economics in which different teaching methods were used. The conventional class included a four-hour lecture using software via the Internet and video-projection. The second class included a two-hour lecture by the teacher and the other two hours were online material. Finally, in the third class, in addition to the online course, the material of all the other classes and videotaped teachings of the conventional lectures were given. It was observed that the students of the first class performed better in exams.

Terry (2000) used three groups of students. The first two groups participated in the lesson of Microeconomics in a traditional way and the third one online. In the third group there was teaching via email, online discussions and conversations. The criterion for the performance of the students was their degree during the semester examinations. The results showed that the third group of students had lower performance than those of the conventional classes. The aforementioned survey continued by Terry et al. (2003). The participants were also divided into three classes, but they used three different methods of teaching, conventional teaching, online teaching and blended learning. The examination of the scores showed that online students had lower performance compared to student of the conventional class, while students of blended learning also had lower performance, but not so important.

During the course "Principles of Economic Theory", Crouse (2002), compared a traditional teaching class with two classes that used online learning. The teaching took place through a list of discussions and lectures of the course using slides, while the communication of trainers and trainees was conducted by email. The students of the traditional class had higher performance compared to ones who participated in online courses.

Coates et al. (2004) examined the performance of two traditional and two web classes in the course "Principles of Management". The online course was based on two payroll software programs, and the results showed that the students of the traditional classes achieved better scores.

Some studies revealed neutral effect such as the one by Mirmirani and Sousa (2005) who examined the difference of using ICT in a traditional learning environment. The courses were conducted by using various technological methods and the traditional lecture. Students stated that the presentation of graphs by computer was a positive experience, but it actually had little impact on performance, because the students did not seem to understand the use of multimedia.

Hall et al. (2000) reviewed the appropriateness of using the software "winecon" as a tool for teaching the course "Principles of Economics" and noted that the students were entertained by the procedure of the course, but they faced with skepticism the ability to have a conversation with your computer or solve queries. Furthermore, they felt the need to include the software in the whole learning process and that the software was directly related to their previous experience and economic knowledge.

In a recent study, Savage (2009) experimentally examined the effect of videotaped lectures, which could later be downloaded from the Internet and studied. The experiment was conducted in the course of "Macroeconomics" and the conclusion of this study was that the hybrid learning application showed no significant effect on students' achievement. 


\section{Metodhology}

In order to test the effectiveness of the blended learning, an experiment was designed. Specifically a one-variable experiment was designed (Gall, Borg \& Gall, 2014). This experiment includes an independent variable or an experimental intervention or an experimental variable and one or more dependent variables or criterion variables (Schechter, 1990). In this research, the teaching method was defined as the experimental intervention and the learning performance and the attitude in class were defined as the dependent variables. In the group which was taught by the blended learning we investigated a) satisfaction from students' learning process and $b$ ) the perceived sense of social presence.

\subsection{Sample}

The sample consisted of twenty $(\mathrm{N}=20)$ students of the 3rd class of High School who were divided into two groups to investigate the problem. The first group of students was taught a particular section of the course via the traditional way of teaching and the second group was taught via the blended learning method. In a survey, the aim is not to study the whole population but a representative sample (Bird et.al., 1999). In literature, a sample size of twenty (20) individuals is usually considered as the minimum number in order to conduct a statistical analysis (Cohen et.al., 1994), while some researchers believe that the sample depends on the restrictions of the research, the required precision, the ratio of non-response and the heterogeneity of the population. This research is defined as small in extent, but the sample is able to show trends and specific views, attitudes and perceptions of the participants in the education process, regarding the effectiveness of blended learning.

\subsection{Research process}

After studying the relevant literature, the experimental procedure, the diagnostic tests and the corresponding questionnaire were designed. The estimated time for the knowledge tests is 30-45 minutes and 10-15 minutes for the questionnaires. The research took place in March 2015. The participants were divided into two groups: one group was the control group and the other was the experimental group, in which the blended learning was implemented.

In the first stage, the questionnaire was filled by both teams during the course "Principles of Economic Theory". Afterwards, the quiz to test the students' knowledge was filled by all students, in order to check whether the two groups were equal for all the parameters which were tested. Meanwhile, both were used to verify any variation in these parameters following the implementation of the blended learning, i.e. to make the final comparison.

In the control group, there was a presentation of the theory by lecture and it lasted 40 minutes. In the experimental group there was only a brief presentation of the platform environment Khan Academy, personal passwords were given to each student and then they were asked to attend this module whenever they wanted on their personal computer for 40 minutes. The platform Khan Academy belongs to a nonprofit organization based in the United Kingdom. It was established in September 2006 and it aims to improve education by providing free education worldwide for everybody. The video platform has subtitles in Greek and it includes primary and secondary education. The teacher creates an online classroom and students log-in, using the credentials which were given the teacher in the classroom. Therefore, the teacher can monitor at any time via reporting of the platform, which video the students have watched and time they 
spent. Thereby, it was certain that both groups, regardless of the teaching method, would spend forty (40) minutes to this specific section. Additionally, a teaching face-to-face session of forty (40) minutes took place in each group, in which the students could ask questions in solve exercises.

In the final stage of the research and after the completion of didactic intervention, the final knowledge control tests took place and the questionnaire regarding the attitudes of each group regarding the course Principles of Economic Theory was filled by both groups.

The control group also filled a questionnaire regarding the satisfaction from the teaching intervention and the social presence.

\subsection{Research Analysis}

For the statistical analysis of data the following methods were selected:

- Statistical indicators of descriptive statistics such as mean (M) and standard deviation (SD) for evaluating all of the variables: The choice of the mean was made because it is generally considered as the best measure of the main tendency of a sample. The standard deviation is an indicator of volatility, it is often used in research studies and it refers to the extent that the values diverge from the average. The mean combined with the standard deviation usually provide an adequate description of how the members of a sample attributed to a specific measurement.

- The $t$ test for independent samples for differences between the two groups regarding to attitude: $\mathrm{T}$ test for independent samples is a process to determine whether the observed difference between the means of two groups of values in the variable $\mathrm{x}$, is statistically significant and it is used when there is no connection between the two sets of values (Gall, Borg \& Gall, 2014).

- The $\mathrm{t}$ test for dependent samples for differences in each group before and after the educational intervention on a) attitudes and b) scoring: $\mathrm{T}$ testing for dependent samples is used when there is a relationship between the two sets of values (Gall, Borg \& Gall, 2014).

- Cronbach's a is used for evaluating the reliability of the questionnaire. It measures the reliability of the internal consistency and it reveals whether different proposals can measure the same concept or variable.

The statistical analysis was performed with the statistical program SPSS 18.

\section{Conclusion}

\subsection{Scoring results}

Comparing the initial performance of students between the two groups before the teaching intervention with the blended learning, we observed that the students' overall performance is not significantly different. Also the range of the scores is low. These indicate that the two groups are on the same level of performance with large internal homogeneity, which enhances the credibility of the research.

After the teaching intervention, it is evident that the students who were taught with the blended learning improved more than the students in the control group. This results from the performance in quizzes, immediately after the teaching intervention. It is a phenomenon observed in many other investigations (Terry, 2003; Talley, 2000), and, according to Yapici and Akbayin (2012), may be due to the fact that the use of online educational materials enables students to do many repetitions and understand the subject through activities, graphics and videos provided by the platform (Narciss, Proske \& Körndle, 2007). Furthermore, they can evaluate themselves through the tests provided by the platform and they can learn at their own pace through the digital material. Especially in modern times that the younger generation is very 
familiar with the new technologies, blended learning can act as an incentive for students to participate in educational process.

However, despite the improved performance of the experimental group, the statistical data analysis tests with the coefficient $t$ for dependent samples showed that differences in performance between the two groups are not statistically significant. These results are consistent with similar studies comparing blended learning and teaching in person which showed no change in the level of performance (Savage, 2009; Sosin et.al., 2004; Brown \& Liedholm, 2002). In some research there were higher scores of the groups taught in the traditional way (Grouse, 2004; Terry, 2000). The diversification of the findings may be due to the differences in content of the courses, the quality of the digital material and the ability of teachers to implement blended learning methods. Additionally, there are differences from the perspective of students regarding their socio-economic situation which can hinder equal opportunities in learning, deficiencies due to knowledge gaps in earlier grades of school and differences in familiarity with new technologies. These factors can be reasons for the diversification of the results.

\subsection{Attitude towards the course of Economics}

In order to investigate the attitudes of students towards the course of Economics, a specialized questionnaire was used. It was filled by all students who participated in this educational intervention, before and after the implementation.

Students of both groups had positive opinion about the course, even before the teaching intervention. The existing positive attitude of the students could stem from the restructuring of the curricula, which focused on presenting the financial courses, with a tendency not to teach "science for science", but in order to teach science as a useful element in the life of every student. It is also a personal choice of each student and not a mandatory course. In addition, the economic concepts and terminology are a part of our daily lives because of the economic recession in Greece, which enhances the interest of students and increases their willingness to actively participate in this course. Finally, there are no significant differences between the two groups as to attitudes before the educational intervention, which enhances the reliability of the results at the end of the investigation.

After the teaching intervention, we noticed that the attitude of students towards the course of the economics is strengthened and it became even more positive, but only in the experimental group. The attitude of students in the control group, after teaching in the traditional way was not improved. This finding is consistent with the research of Navarro (2000), who investigated the effect of blended learning in economics, as part of a new educational program. The research revealed that the satisfaction and the attitude of learners towards the course was the same or even better, than those who followed the traditional way of teaching. The change in a student's attitude towards a course is considered as crucial because, according to Simpson et.al. (1994), the development of programs that positively influence learners towards science may lead to changes in their behavior. There is also research (Seegers \& Boekaerts, 1993) which concluded that the students' attitude affect significantly their performance.

After the analysis of the questionnaire, three different axes were investigated regarding the attitude of the students: interest, difficulty and importance. There were no statistically significant differences between the two groups before the teaching intervention regarding these axes. The axis of interest was considered as the most important in the two groups. This shows the dynamics of the course because of its usefulness of the daily life.

The implementation of blended learning showed statistically significant differences between the two 
groups mainly in the dimension of interest, since the control group remained unchanged, while the experimental group improved significantly, while in the other two axes, no significant changes were observed. There is also improvement in the experimental group in the dimensions of interest and importance before and after the teaching intervention. Piburn (1993) states that the variety of methods during the teaching process is a key factor and it makes the lesson more interesting. In this research, the combination of new innovative educational methods with the supportive presence of the teacher in the experimental group and the motivation of the exam maybe affected positively the attitude of the students.

\subsection{Students' satisfaction}

Another parameter measured by this research was the level of students' satisfaction. This parameter was investigated only in the experimental group, by their experiences of using the educational platform but generally by their participation in the implementation of a blended learning method. Meeting the needs of the students during an educational intervention is of fundamental importance, since many researchers argue that it does not only positively affects students' performance but it is also directly related to the retention of information in memory (Booker \& Redmon, 2005). We used a specific questionnaire to assess students' satisfaction and the results showed the positive effect of blended learning in the satisfaction of students. The willingness of students to participate in another online course in the future, showed the high interest for further participation in educational processes involving the implementation of new technologies.

The only negative response referred to the low stimulation of the platform to use the feature of making questions, after the module which they attended. This high level of satisfaction was also observed in other investigations (Navarro, 2000) and it can help to create a favorable climate for the implementation of blended learning in education.

\subsection{Social presence}

The results of the questionnaire which was used to assess the development of a sense of social presence, showed a neutral attitude. The correlation of social presence and the distance between the students and the teacher is important. Furthermore, the image and sound is crucial to social presence. Yamada (2009) argues that the voice communication significantly affects the learners and the existence of the image of the teacher reinforces the sense of physical contact and therefore the feeling of social presence. The lack of physical image of the teacher in the video platform is likely to be the cause of low sense of social presence in the experimental group.

The connection between the students' satisfaction and the feeling of social is investigated by Richardson and Swan (2003). Additionally, the only way of communication among students while using the platform was by making questions. It is an issue that directly relates to recent surveys that argue a high degree of correlation between cooperative learning and social presence (So \& Brush, 2008). However, there is a positive view of social presence expressed by students, as they seem to feel part of a wider learning community.

\section{Discussion}

This research is an attempt to implement and study the blended learning approach. The results of this quantitative research showed a slight improvement of students' performance in the experimental group, while the control group was static. There were positive effects on the attitude of students in the 
experimental group towards the course of Economics and the students' satisfaction improved. The sense of social presence was moderate in the members of the experimental group.

However, this research was limited. The most important issue is to conduct further research that would use quantitative and qualitative data collection methods and, through the triangulation of the results, there will be more accurate conclusions. The creation of an educational curriculum with reduced teaching hours in the classroom would be an alternative for students' parents who cannot afford high tuition fees. It could also give equal opportunities in remote regions of the country, as it would significantly reduce the students' travel. Furthermore, distance learning could be the solution to reduce the operating costs of the entire education field.

\section{References}

Agarwal, R., \& Day, A. E. (1998). The Impact of the Internet on Economic Education, the Journal of Economic Education, spring, 99-110.

Bird A., Wolffe A.P. (1999) Methylation-induced repression-Belts, braces and chromatin. $99,451-454$

Bonk, C. J., Olson, T. M., Wisher, R. A., \& Orvis, K. L. (2002). Learning From Focus Groups: An Examination of Blended Learning. Journal of Distance Education, 17(3), 97-118.

Booker, Q. \& Rebman, C. (2005). E-student retention: Factors affecting customer loyalty for online program success. Issues in Information Systems, 6(1), 183-189.

Brown, W., Liedholm, C. (2002). Can Web courses replace the classroom in principles of microeconomics?. American Economic Review, 92 (May), 444-448.

Coates, D., Humphreys, B., Kane, J., \& Vachris, M. (2004). No significant distance between face-to-face and online instruction: evidence from principles of economics. Economics and Education Review, 23(5), 533-546.

Cohen, L., Manion, L., \& Morrison K. (1994). Research Methods in Education. London: Routledge Falmer.

Crouse, L. (2002). Comparisons of the Educational Outcomes from Distance Delivered versus Traditional Classroom Instruction in Principles of Microeconomics. MS thesis. Virginia Tech.

Gall, M. D., Gall, J. P. \& Borg, W. R. (2006). Educational Research: An Introduction (8th Ed). Boston: Pearson International Inc. House, E. R. (1991), Realism in research. Educational Researcher, 20, 2-9.Somekh, B. (1983)

Hall, L., Ainley, P. \& Ryan, M. (2000). Student perceptions of WinEcon as a learning tool-an evaluation report. School of the Greenwich Compulsory Education and Training, University

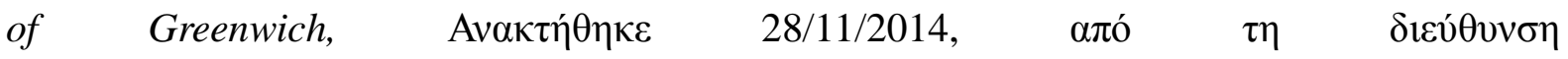
http://www.winecon.com/evaluation/hall2000.doc

Holmberg, B. (1983). Guided didactic conversation in distance education. In D. Sewart, D. 
Keegan, \& B. Holmberg (Eds.), Distance Education: International Perspectives (pp. 114-122). New York: St. Martin's Press.

Lim, P. (2003). Information and Communication Technologies (ICT) Addressing the Challenges of Economics Education: To Be or Not To Be? International Review of Economics Education, 2(1), pp. 25-54

Mirmirami, S. \& Sousa (2005). The Impact of Technology in Teaching Freshman Economics: A Quantitative Approach. Journal of College Teaching \& Learning 2(12), 17-24.

Narciss, S., Proske, A., \& Koerndle, H. (2007). Promoting self-regulated learning in web-based learning environments. Computers in Human Behavior, 23(3), 1126-1144.

Navarro, P. (2000). Economics in the Cyber classroom. Journal of Economic Perspectives, $14(2), 119-132$.

Nelson, L. (1997). Recent trends in economic education, ERIC clearinghouse for social

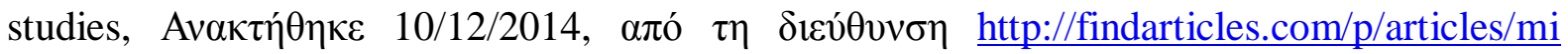
pric/is 199707/ai 4134111599/?tag=content; coll.

Piburn, M. D. (1993). If I were the Teacher...Qualitative Study of Attitude toward Science. Science Education, 77(4), 393-406.

Richardson, J. \& Swan, K. (2003).Examining social presence in online cources in relation to students' perceived learning and satisfaction. Journal of Asynchronous Learning Networks, 7, 68-87

Savage S. J., (2009). The Effect of Information Technology on Economic Education, Journal of Economic Education, 40 (4), 337-353.

Schechter, M. (1990). The relative instructional efficiency of small group computer based training. Journal of Educational Computing Research, 6, 329-341.

Seegers, G., \& Boekaerts, M. (1993).Task motivation and mathematics achievement in actual task situations, learning and Instruction, 3(2), 133-150.

Simpson, R. D., Koballa, T, R., Oliver, J.S., \& Crawley,P. E. (1994).Research on the affective dimension of science learning. In D. L. Gabel (Ed.), Handbook of Research on Science Teaching and Learning (pp. 211-234). New York: Macmillan.

Sosin K., Blecha B., Agarwal R., Bartlett R., \& Daniel J. (2004, May). Efficiency in the Use of Technology in Economic Education: Some Preliminary Results. American Economic Review, 2, 253-258.

Talley, D. (2000). Technology and Teaching: Learning in a High-Tech Environment. Presented at the Midwest Economics Association, April, Chicago.

Terry, N. (2000). The effectiveness of virtual learning in economics, Journal of Economics and Economic Education Review, 1, 93-99.

Terry, N., Lewer, J., \& Macy, A. (2003).The Efficacy of Alternative Instruction Modes in 


\section{Macrothink Institute ${ }^{\mathrm{TM}}$}

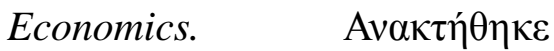

International Journal of Learning \& Development

ISSN 2164-4063 2016, Vol. 6, No. 1

http://ssrn.com/sol3/papers.ctm?abstract id=392561

Yamada, M. (2009). The role of social presence in learner-centered communicative language learning using synchronous computer-mediated communication: Experimental study. Computers \& Education, 52, 820-833.

Yapici, U. I., Akbayin, H. (2012).The effect of blended learning model on high school students' biology achievement and on their attitudes towards the Internet. The Turkish Online Journal of Educational Technology, 11(2), 228-237. 